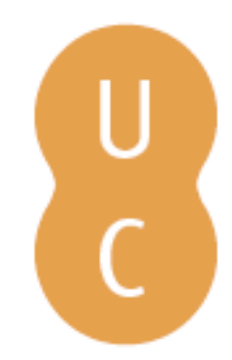

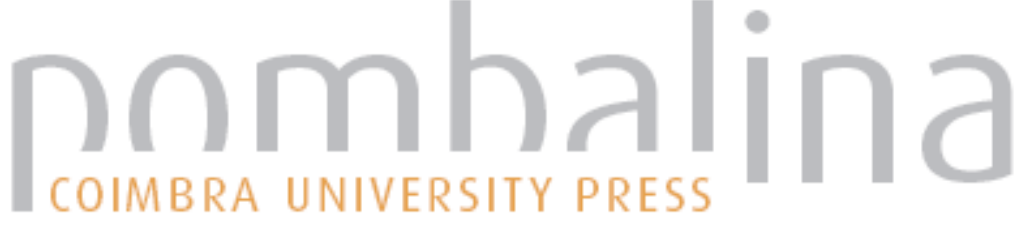

\section{A Paixão do Conde de Fróis: paródia e subversão}

Autor(es): $\quad$ Arnaut, Ana Paula

Publicado por: Imprensa da Universidade de Coimbra

URL

persistente:

URI:http://hdl.handle.net/10316.2/37029

DOI:

DOI:http://dx.doi.org/10.14195/978-989-26-0548-7_9

Accessed : $\quad$ 26-Apr-2023 10:37:22

A navegação consulta e descarregamento dos títulos inseridos nas Bibliotecas Digitais UC Digitalis, UC Pombalina e UC Impactum, pressupõem a aceitação plena e sem reservas dos Termos e Condições de Uso destas Bibliotecas Digitais, disponíveis em https://digitalis.uc.pt/pt-pt/termos.

Conforme exposto nos referidos Termos e Condições de Uso, o descarregamento de títulos de acesso restrito requer uma licença válida de autorização devendo o utilizador aceder ao(s) documento(s) a partir de um endereço de IP da instituição detentora da supramencionada licença.

Ao utilizador é apenas permitido o descarregamento para uso pessoal, pelo que o emprego do(s) título(s) descarregado(s) para outro fim, designadamente comercial, carece de autorização do respetivo autor ou editor da obra.

Na medida em que todas as obras da UC Digitalis se encontram protegidas pelo Código do Direito de Autor e Direitos Conexos e demais legislação aplicável, toda a cópia, parcial ou total, deste documento, nos casos em que é legalmente admitida, deverá conter ou fazer-se acompanhar por este aviso.

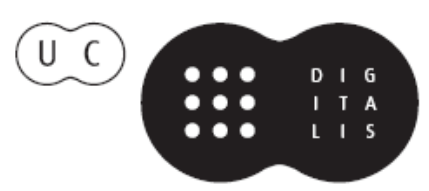


do Tempo e da História

- Mário de Carvalho e a reflexáo metaficcional sobre o futuro do romance - Sátiva e o cepticismo: configuração de personagens em Mário de Carvalho - Escrever tem arte e tem segredos... Era bom que trocássemos umas ideias sobre o assunto - O processo criativo em Era bom que trocássemos umas ideias sobre o assunto - Intertextualidade e metaficção em Fantasia para dois Coronéis e uma Piscina, de Mário de Carvalho - Trimalquiāo, os coronéis e a piscina: retrato impiedoso de um pais em crise $\bullet A$ Paixão do Conde de Fróis: paródia e subversão • "Como dizia o outro": a presença dos Clássicos em Mário de Carvalho - Cultura Clássica em Um

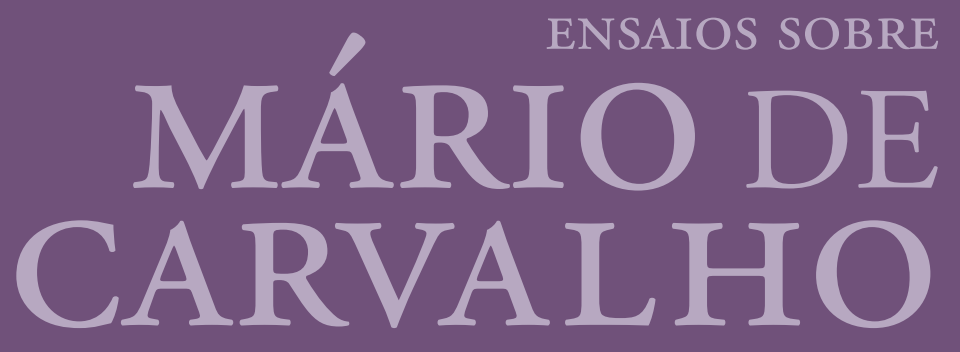

Maria de Fátima Silva Tereza Virgínia Ribeiro Barbosa COORD. IMPRENSA DA UNIVERSIDADE DE COIMBRA COIMBRA UNIVERSITY PRESS

elemento mouro como simbolo de alteridade $e$ barbárie em Um deus passeando pela brisa da 


\title{
A Paixão do Conde de Fróis: paródia e subversáo
}

\author{
Ana Paula Arnaut \\ Centro de Literatura Portuguesa / FLUC
}


(Página deixada propositadamente em branco) 
A Paixão do Conde de Fróis de Mário de Carvalho $\left(1986^{2}\right)$ consubstancia a ilustração perfeita de uma certa tendência post-modernista que parece considerar que "o trabalho de emendar é o único que nunca se acabará no mundo", até porque "o reino da terra é dos que têm o talento de pôr o não ao serviço do sim" ${ }^{3}$, mesmo que esse "não" surja apenas travestido de problematização mais do que de negação absoluta. A citação é de um outro escritor, José Saramago, mas não temos dúvidas em usá-la a propósito do romance de Mário de Carvalho. Este recupera o tempo perdido da História com a plena consciência de quem entra num jogo em que a ironia e a metaficção, bem como as emendas semânticas e formais e os acrescentos da lavra da sua imaginação, fazem implodir sentidos e factos tradicionalmente tidos por inatacáveis. Longe, portanto, de uma atitude discreta, respeitosa e (pedagogicamente) nostálgica, que consistiria em "reproduzir ponto por ponto os factos conhecidos", Mário de Carvalho entretece "dados históricos não mais que suficientes num tecido ficcional que se manterá predominante"4.

Neste romance, onde claramente se afirma a possibilidade de dispensar alguns elementos caracterizadores do passado ${ }^{5}$, as ilaçóes ideológico-subversivas são, por conseguinte, sobejamente interessantes, quer no que diz respeito à História religiosa quer no que se refere à História laica, as duas faces de uma mesma moeda que, afinal, se revelam indispensáveis para o conhecimento de uma época.

Considerado por Fernando Mendonça como "no fundo, uma história de padres[,] [p]ois, como o próprio A. diz (72), «padres é o que não falta na literatura portuguesa»" -se de acintoso e jocoso espírito crítico. Um espírito crítico que, pela leitura inversa e irónica das homologias traçadas, serve os propósitos de uma grotesca caricatura de uma parcela da sociedade de setecentos:

A Paixão do Conde de Fróis seria uma historieta sem consequências, se não fosse o minucioso e expectante desenvolvimento da acção. No percurso narrativo, vão-se construindo simbolicamente os aspectos que caracterizam a sociedade portuguesa, a do século XviII, que no fundo

\footnotetext{
1 Texto retirado e adaptado de Arnaut, 2002: 324-354.

2 Todas as citaçôes são feitas a partir da $3^{a}$ edição (1993).

3 Saramago, 1989: 14 e 330, respectivamente.

4 Saramago, 1990: 19.

5 Carvalho, 1993: 173.

6 Mendonça, 1997: 104.
} 
é a dos séculos subsequentes. A nobreza teimosa, surda aos apelos do povo, o povo que é o pau-mandado da nobreza e náo sabe porquê. $\mathrm{O}$ clero, que na sombra manipula a nobreza e o povo. Este é, de facto, o pano de fundo de $A$ Paixão do Conde de Fróis, a paixão de ser capaz de reconstruir uma fortaleza absolutamente inútil7.

Mas o título remete para mais do que essa paixão que torna a personagem capaz de reconstruir a fortaleza. De acordo com a linha subversiva de consecução do alternativo tratamento post-modernista da(s) História(s), julgamos que o que também se pretende é traçar um paralelo, dessacralizante e risível, com o solene sentido bíblico da paixão de Jesus Cristo, que desde a prisão no horto à expiração na cruz sofre inúmeros e indignos tormentos.

Do mesmo modo(!), também o nosso protagonista, no início apresentado como dado a estroinices de índole diversa (é precisamente por isso desterrado para S. Gens, onde deve assessorar o comandante da praça), sofre, progressivamente, uma semelhante via crucis de incompreensão, desencadeada pelo inexplicável e assombroso empenho com que pretende defender a praça que acaba por interinamente comandar.

Além disso, e agora no que respeita à incorporação irónica de referências intertextuais num discurso histórico consagrado e não sagrado, a personagem é também pomposamente (e premonitoriamente) descrita pelo parlamentário espanhol (esse que se desloca à praça de S. Gens para negociar a rendição dos sitiados) como misto de Calígula e de Heliogábalo ${ }^{8}$. Os epítetos nada abonatórios ridicularizam, pela desproporção da comparação, a figura deste conde que, pela sua obsessão e teimosia compulsiva, granjeia a antipatia do povo. $\mathrm{O}$ mesmo povo que, motivado pelo padre capelão, manhosamente frustra os intentos de manutenção do domínio de

\footnotetext{
7 Ibid.:.104.
}

8 Ver ibid.: 151. Calígula (n. 12 e assassinado a 41) inicia o seu reinado sob ventos auspiciosos mas, ao tomar conhecimento de que largos milhares de vítimas haviam sido sacrificadas aos deuses para que estes o livrassem da doença que sofria, torna-se delirante de sangue e de uma brutalidade que não mais o abandona. Heliogábalo (n. 204, m. 222), vítima também de assassinato, protagoniza um reinado de devassidão, infâmia e crueldade. Interessante e não menos premonitoriamente simbólico e irónico parece ser o facto de $S$. Gens ser o espaço escolhido para o desenrolar da acçáo, pois, de acordo com a hagiografia, este santo que dá origem ao topónimo foi um mártir romano. Em qualquer dos casos apontados ressalta a ideia náo apenas de morte violenta, mas de morte provocada por outrem - precisamente o que acontece ao conde de Fróis cuja morte decorre de ruidosa manobra da população, que prefere entregar-se aos sitiantes a continuar a sofrer as suas investidas. 
uma praça que, aqui, parece duplicar, com cores inversas mas não menos irónicas e caricatas, essa outra de facto protagonista de cerco e de conquista historicamente atestados e imputados ao marquês de Sarriá.

Referimo-nos ao episódio do cerco de Almeida, entre 7 e 25 de Agosto de 1762. Com efeito, a determinação obsessiva e doentia do marechal de campo Alexandre Palhares parece ter inspirado Mário de Carvalho na construção do seu protagonista. No entanto, se ambas a figuras se aproximam pela incompetência demonstrada (e pelo ridículo das situaçóes em que se envolvem), elas afastam-se na medida em que o primeiro contraria ordens superiores, acabando por optar pela capitulaçáo da praça, porque é movido por uma extremosa preocupaçáo em defender os interesses da populaçáo ameaçada pelos intensos bombardeamentos dos sitiantes.

Ora, em A Paixáo do Conde de Fróis, se é certo que o grotesco nobre é apresentado como tendo sofrido uma metamorfose comparada à de "S. Paulo a caminho de Damasco", a verdade é que esta comparação não pode senão ser lida à luz de um espírito contrário e, mais uma vez, dessacralizante. Não se trata, pois, de uma transformação conducente ao dealbar de uma mais humana e generosa personalidade, trata-se, sim, de uma intensificação de características que de um estroina civil fazem um compenetrado estroina militar, o qual, empenhado na criação de um mundo muito seu, não hesita em abater o tendeiro revoltoso que se preparava para, das muralhas, agitar o pano branco da rendiçáo:

O pano branco removeu-se junto à muralha, no meio do tropel. Oscilou, numa hesitaçáo breve. Logo o tendeiro o tomou, e com ele alçado, subiu a correr pela escada das muralhas, sem que alguém, nem os soldados de serviço lá em cima, lhe travasse o passo. Prosseguiu pelos adarves, aos saltos, com a bandeira bem alto. Depois parou, fazendo-a pendular largamente dum lado para o outro.

$\mathrm{O}$ tiro, seco, reboou, levantando um estralejar arrastado de pequenas ressonâncias pelas paredes além ${ }^{10}$.

A preocupação em atingir uma excessiva competência de estratega redunda, portanto, em derradeira instância, numa incompetência caricata que se traduz na impossibilidade de gerir diplomaticamente as relaçóes entre civis, padres incluídos, e militares.

\footnotetext{
9 Carvalho, 1993: 27.

10 Ver ibid.: 166-168.
} 
Se os conflitos que estabelece com a sociedade envolvente parecem fazer do protagonista um tipo de herói canónico, nomeadamente o do Romantismo de oitocentos, a verdade é que, mais uma vez, prevalece a subversão e a consequente dessolenização. Características que decorrem, agora, não apenas de uma englobante urdidura irónica ${ }^{11}$ (onde, como veremos, desempenham papel fundamental os comentários metaficcionais do narrador que do século xx revisita o passado), mas também do modo como grotescamente se delineiam os traços físicos da personagem em questão:

Sobre o baixo, escanzelado, com o ombro esquerdo ligeiramente descaído, em consequência duma justa de touros infeliz que lhe amassou costelas e retorceu a clavícula, parecia ligeiramente disforme, com os braços de comprimento desmesurado e pernas muito esguias, tortas e nodosas. O olhar era mortiço, cínzeo, parado, sonolento. A face comprimia-se abaixo das fontes, para recuperar espaço na zona da testa, larga e protuberante, a contrastar com o afunilamento do queixo. Não havia peruca que lhe servisse, antes se dispunham tortas e indiscretas logo ao primeiro uso, deixando entrever, por debaixo, os cabelos cortados cerce, finos e arruivados.

A boca traçava-lhe a cara, quase de extremo a extremo (...).

A voz saía-lhe roufenha, pesada, arrastada, quando não hesitante ${ }^{12}$.

O contraste dessacralizante, e que sempre redunda em sorriso irónico, entre a solenidade das referências intertextuais e o ridículo de uma situação que se insiste em levar demasiadamente a sério, seja pelo conde de Fróis seja pelo espanhol marquês de Alagon (igualmente casmurro nos seus desejos de vencer um cerco que, em última instância, se fica inadvertidamente a dever a um carvoeiro que se arroga o direito de tentar afugentar os espanhóis ao hiperbolizar as grandezas das defesas de S. Gens ${ }^{13}$ ), ocorre, ainda, em outra situação. Reportamo-nos ao episódio em que, a propósito da

11 Sobre a ironia nesta obra de Mário de Carvalho, bem como sobre as possíveis ilaçôes cómicas, ver Sequeira, 1996: 23-27 e 83-90.

12 Carvalho, 1993: 74-75.

13 Ver ibid.: 120 (ainda a propósito do episódio do carvoeiro, ver ibid.: 105). Depois do interrogatório em que a personagem declara a existência de "mais de vinte canhōes e quatro batalhóes, fora os homens da milícia, sob o comando do conde de Fróis, experimentado oficial das guerras de Mazagão e da Índia", o marquês de Alagon, "passou em torno um olhar triunfante sobre as faces perplexas e inquietadas do seu Estado-Maior", ao mesmo tempo que mentalmente reprovava os "senhores oficiais que queriam passar de largo..." 
preparação dos trabalhos deste cerco de uma praça que nem sequer "vinha no mapa", se estabelece a comparação entre Sarriá e o responsável por esse outro cerco de dimensóes escatológicas protagonizado pelo "imperador Tito em frente de Jerusalém"14.

$\mathrm{O}$ que assim se consegue, afinal, é a manutenção de mais uma das características do Post-Modernismo enquanto fenómeno por vezes contraditório, já que

usa e abusa, instala e depois subverte, os próprios conceitos que desafia - seja na arquitectura, na literatura, na pintura, na filosofia, na teoria estética, na psicanálise, na linguística ou na historiografia ${ }^{15}$.

É caso para perguntar, pois, "Que seria de nós se não fosse o deleatur"16?. Sem a sua carga simbólica, que aqui convocamos para legitimar a paródia à(s) $\mathrm{H}(\mathrm{h})$ istória(s) do cerco da praça de $\mathrm{S}$. Gens, que mantém a menção a outros referentes históricos (Pacto de Família, o contexto englobante de um cerco que decorre na Guerra dos Sete Anos, reinado de D. José, os nomes de Sarriá ou de Lippe-Schaunberg), não seria possível a plena aceitação da modelização pessoal que se inscreve no xadrez narrativo. Não seria também possível o acatamento da subversão da máscara séria da História levada a cabo neste romance cujas páginas, ainda que indirecta e enviesadamente, expóem e denunciam, auto-reflexivamente, o carácter viciado e selectivo do trabalho de pesquisa dos historiadores.

Ao evocar o episódio histórico também conhecido como «Guerra Fantástica», Mário de Carvalho joga e entretece os dados históricos com os resultantes da sua imaginaçáo de um modo mais discreto do que o que observamos em romances de outros autores, mas a verdade é que o resultado não se traduz numa revisitação do passado menos inocente ou mais nostálgico. Assim, apesar de na dedicatória de A Paixão do Conde de Fróis se aproveitar o ensejo para alvitrar a inserção do romance no campo da fantasia, ou apesar de, desde o início, ser possível detectar a presença de um tom irónico e jocoso, o leitor mais ingénuo (ou menos habituado às convençóes subversivas do Post-Modernismo) é certamente impelido a

pois, "já se via a chegar ao cerco de Bragança com a artilharia e tomadias de S. Gens, pondo em evidência a inépcia dos que, antes dele, haviam subestimado a praça”.

\footnotetext{
14 Ibid.:.174 (118 para a referência anterior).

15 Hutcheon, 1991: 19.

16 Saramago, 1989: 16.
} 
esquecer estes indícios e a aceitar o universo narrado como credível, porque conforme, neste primeiro andamento da narrativa, a um pacto de leitura canónico, já cultivado nos romances históricos de Alexandre Herculano, por exemplo. De facto, não apenas se não expóem ou debatem abertamente questôes colateralmente relacionadas com a reconstituição histórica e com a aberta problematização da História, como, além do mais, os exercícios metaficcionais ou auto-reflexivos apenas se fazem sentir de forma mais sistemática quando a engrenagem da $\mathrm{h}(\mathrm{H})$ istória vai já adiantada, sensivelmente a partir do primeiro terço da obra.

O desvendamento metaficcional de que a narrativa é manipulada pela entidade que do presente coevo preside ao discurso (disso se valendo para, numa íntima e tácita relação com o destinatário extra-literário atestar, apesar de tudo, a veracidade dos factos ${ }^{17}$ ) só ocorre claramente quando, a propósito da chegada de uma missiva trazida por um anspeçada do regimento de Miranda (e cujo conteúdo permanece desconhecido para o padre capeláo), se comenta sobre o privilégio de conhecimentos que autor e leitor virtualmente detêm ${ }^{18}$.

A partir deste momento sucedem-se e intensificam-se os comentários que, de forma mais ou menos explícita, anunciam uma orientação da leitura em estreita cumplicidade com o leitor, ao mesmo tempo que atestam a subjectividade da interpretação dos sujeitos/materiais históricos:

Era destarte, sem tirar nem pôr, que o conde interpretava aquela tineta do padre de o arredar da praça, e distrair dos seus deveres e compromissos. Interpretava bem, interpretava mal? O leitor o dirá. Mas convém ir-se lembrando de que o padre, ao invés de muito sacerdote caceteiro e brigão do seu tempo, o que mais prezava era o sossego e a pacificação;

17 Carvalho, 1993: 105 e 125, respectivamente: "Tanto traste foi enterrado debaixo da lareira, ou entalado nos interiores de granito, que ainda hoje os amadores de antiqualhas e bricabraques lucrariam com a pesquisa, nanja os de panelas de ouro, que não as havia”, "Habitualmente os leitores estarão afeiçoados a um certo dramatismo nestas mortes. Considera-se sempre que o passamento de alguém é um acto tão importante que há-de rodear-se e empavesar-se de trejeitos e ademanes rituais e anunciadores. Nos filmes de agora, por exemplo, como é que é? Os cavaleiros acusam o golpe, estorcem-se, levam a mão à ferida, balanceiam de frente para trás e de trás para a frente, dobram-se sobre a montaria, descaem a cabeça à altura do arção, e lá acabam por cair em grande espectacularidade. Na vida real, como esta que se conta é, não ocorrem assim as coisas" (destacados nossos).

18 "Mas já que o padre não soube [o que se dizia na carta], saibamo-lo nós que, autor e leitor, temos esse privilégio", ibid.: 58. 
Qualquer apreciaçáo sobre um homem, desde que se não seja deus - é o caso do autor que suspeita de que, neste particular, também tem a cumplicidade do leitor -, vem sempre frouxa, contingente e incompleta. Serve para se ir vivendo. No caso dos autores, para se ir escrevendo;

Eu agora simplifiquei. Os projectos do padre não eram assim tão pensados;

Importa agora dizer como era este padre? Penso que náo, que vai ele muito aviado com o feitio que lhe foi conferido e não carece de mais acrescentos. Padres é o que náo falta na literatura portuguesa. Sáo mesmo de longe muito mais abundantes que os condes, de modo que posso considerar a imaginaçáo do leitor suficientemente habilitada a compor este sacerdote, no físico e demais atributos aparentes. Basta que era cinquentáo, baixo e largo./E, retomando o fio - que a interrupção aproveitou um instante em que o étimo e a declinação de nudiustertius foram ali esmiuçadas -, ouve-se o padre perguntar — Então, senhor conde, e como vai isto de guerra? (... $)^{19}$.

Estes comentários (que enviesadamente contaminam a linearidade e a veracidade dos factos históricos expostos) começam a obrigar, por conseguinte, a uma reapreciação do já lido. Em consequência, eles instauram, também, uma mais premente necessidade de pesquisa paralela em relatos oficialmente acreditados a fim de confirmar as suspeitas tardiamente instauradas de que, afinal, A Paixão do Conde de Fróis não é uma mera revisitação do passado histórico.

Pelo contrário, o romance assume-se como uma recriação subjectiva de onde, por um lado, se não ausentam possíveis teias ontológicas ao real do que foi e do que aconteceu, e em que, por outro lado, é legítimo ler a ideologia de um autor/narrador subtilmente empenhado não na construção de um suplemento da historiografia oficial (como o faria Walter Scott ou, posteriormente, os seguidores de uma linha tradicional ${ }^{20}$ ), mas na utilização lúdico-irónica do material histórico.

Desta utilização não se encontra isenta, convém sublinhar, uma linha de acintosa crítica, já inicialmente indiciada a partir da citação de Fernando

19 Ibid:.72, 73, 76 e 80 (destacados nosso).

20 Ver Wesseling, 1991: 42. 
Mendonça, a um certo conjunto de padres que desde tempos imemoriais percorrem a literatura portuguesa.

Para além dos notórios traços caricaturais respeitantes à personalidade do mal amado capelão da família Fróis, vítima primacial dos acintes do narrador que, desse modo, relega para segundo plano o 'pobre' vigário de S. Gens, é de toda a utilidade apontar a influência e a importância desta personagem no desenrolar último dos acontecimentos que culminam na morte do conde.

É como se, obliquamente, se atestasse o exercício extensional de uma manipulaçáo provinda da entidade religiosa, que, sempre mais preocupada em fazer valer pessoais desígnios e uns tantos privados confortos, náo olha a meios para conseguir os seus fins, mesmo que tal implique, numa exortação muito pouco ortodoxamente católica, pedir auxílio ao diabo, caso este esteja disponível ${ }^{21}$ !

Se em algumas das apreciaçóes feitas é visível o prolongamento do paradigma metaficcional a que vínhamos aludindo ${ }^{22}$, a verdade é que ele se estende, ainda, numa aliança aparentada com técnicas cinematográficas, à movimentação protagonizada pelo narrador para melhor observar e reger os acontecimentos:

Deixemos estas entretengas mornas de tiro demonstrativo, e deixemos o padre - ala que se faz tarde! - a caminho de casa, e apreciemos melhor como tudo se passou à janela e perto do conde, que é o sítio de melhor vista;

Prossigam eles as congeminações e os inventários, sisudamente, que o tempo nos dá para irmos ao arraial espanhol, ver como se dispóem as coisas. (...) Vista de perto ["Toda aquela gente"], com olhos do autor (que os tem de gato, assim lhe fosse também o fôlego...), na noite negra, a azáfama lembra o remexer de uma colónia larvar;

21 Carvalho, 1993: 54. Registemos ainda a emblemática súmula que o narrador faz desta personagem: "A paciência grande é a dos Beneditinos ou a dos santos. Ele não era nem uma coisa nem outra (...)" (65).

22 A propósito da possibilidade de comparação entre o capelão e o espanhol cónego adunco (ibid.: 115-117), por exemplo, o narrador/autor arroga-se o direito de peremptoriamente afirmar o definitivo afastamento do segundo da história que conta. 
Tudo visto, volte-se às muralhas e, dentro delas, à torre de menagem onde o conde conferencia com os seus oficiais e o prior vai dormitando, à espera $(\ldots)^{23}$.

O que assim se póe em relevo é um claro e assumido domínio sobre a matéria contada ${ }^{24}$, velada por vontade própria ${ }^{25}$ ou por respeito a uma verdade que sempre se contraria e ficcionaliza ${ }^{26}$ porque, afinal, não há que respeitar uma representação realista do mundo histórico. Como depreendemos de confissão ostensiva e impertinentemente tecida a propósito de certa táctica militar, não existe, inclusivamente, qualquer pudor em assumir a ignorância e/ou o desconhecimento de coisas sobre as quais sabe tanto como de grego ${ }^{27}$.

Apesar de frequentemente se chamar a atenção para a delimitação de fronteiras entre História e ficção (quer pelos registos metaficcionais, manifestos ou dissimulados quer por outras estratégias discursivas, entre as quais contamos a ironia e a manipulaçáo dos registos de linguagem), o certo é que esta diferenciação acaba por se diluir, até porque o narrador, ou o autor, pontualmente evidencia o respeito pela verdade histórica, como sucede no seguinte exemplo:

23 Ibid.:167, 174 e 176 (destacados nossos).

24 "Enquanto aguardava os outros, garatujou uma lista de assuntos numa ardósia, que a ocasião requeria poupança de papel e nem em tudo, por mais prudente, o conde se havia sabido prevenir, como melhor veremos mais adiante"; "A ordem, numa longa fieira, desde o pormenor miúdo às questôes decisivas, era longa, enfadonha, e se o leitor a náo dispensar, dispenso-a eu. Basta referir que os três homens andaram às voltas com o incêndio na casa do feno, procurando remédio para o sustento do gado, e chegaram prestes à conclusão de que havia pouco fornecimento de madeiras e carvốes para o lume (...)”, ibid: 172 e 173, respectivamente (destacados nossos).

25 "Grande confissão [a do "senhor conde"] havia de ser, tomando em linha de conta os acontecimentos últimos. Respeitemos-lhe o sigilo", "Num ressalto, meio ocultada por entulhos, escoras, e por uma parede nova de reforço, furava a velha porta gótica, chamada da traiçáo, como em outras praças, por razóes semânticas que náo cabe aqui referir”, ibid.: 180 e 196 respectivamente (destacados nossos).

26 "Por pudor, omitam-se as alusões, nem todas verdadeiras, com que o capitão de cavalaria foi brindado, e cheguemo-nos mais ao final da conversa, de novo derivada para a apreciação das circunstâncias do cerco (...), ibid.: 191.

27 "Era própria e adequada esta táctica militar? Não mo perguntem a mim que me limito a contar a história e sei tanto de assédios militares como de grego. Era assim que eles procediam. Se bem, se mal, julgue-o o leitor, ou, se não quiser julgá-lo, suspenda o juízo, como o outro... Dessarte me avenho eu...", ibid.: 185. 
Seria talvez a altura de o autor, que nunca no decorrer da narraçáo deixou de mostrar alguma admiraçáo pelo conde e governador de $S$. Gens, lhe pôr na boca ou no pensamento uma tirada dramática, de burilado recorte, dando conta do agastamento com a traição que assim era perpetrada. Mas a história tem os seus pruridos de verdade que se sobrepóem às parcialidades do autor e este vê-se constrangido a relatar o que ao conde calhou dizer, e não o que ele gostaria que o conde dissesse ${ }^{28}$.

Em suma, talvez para a História, e para as histórias da História, valha apenas a justíssima asserção de que "a verdade não pode ser mais do que uma cara sobreposta às infinitas máscaras variantes" 29 . Estas concretizam-se, em derradeira instância, não só na consecução do que John Woods designa por modalidades mistas de existência ${ }^{30}$, isto é, na convivência no universo narrado de personagens, acontecimentos e lugares aceites como históricos, com personagens, acontecimentos e espaços ficcionais, mas também no facto de em cada uma destas categorias poderem, eventualmente, coexistir as duas linhas de força: a histórica e a ficcional. "En ce sens", como diz Ricoeur, "la fiction emprunterait autant à l'histoire que l'histoire emprunte à la fiction" 31 .

\footnotetext{
28 Ibid.: 199-200 (destacados nossos).

29 Saramago, 1989: 26.

30 Woods, 1974: 41-42.

31 Ricoeur 1983: 154.
} 


\section{Bibliografia Geral}


(Página deixada propositadamente em branco) 


\section{Ediçôes de Mário de Carvalho}

(21990), Contos da sétima esfera. Lisboa, Caminho.

(1991), Quatrocentos mil sestércios. Lisboa, Caminho.

(71991), Casos do beco das sardinheiras, Lisboa, Caminho.

(31993), A Paixão do Conde de Fróis. Lisboa, Caminho.

(1996), Os Alferes. Lisboa, Caminho.

( $\left.{ }^{3} 1996\right)$, O livro grande de Tebas, Navio e Mariana. Lisboa, Caminho.

(1997), Um deus passeando pela brisa da tarde, Lisboa, Caminho.

$\left({ }^{3} 1997\right)$, Fabulário. Lisboa, Caminho.

(52003), Era bom se trocássemos umas ideias sobre o assunto. Lisboa, Caminho.

(32004), Fantasia para dois Coronéis e uma Piscina. Lisboa, Caminho.

('2006), A inaudita guerra da Avenida Gago Coutinho. Lisboa, Caminho.

(2008), A sala magenta. Lisboa. Caminho.

(2010), A Arte de Morrer Longe. Lisboa, Caminho.

\section{Estudos}

Adorno, T. W. ('1983), "Posição do narrador no romance contemporâneo". In: Benjamin, Honkheimer, Adorno, Habermas. Trad. port. José L. Grünnewald et alii. São Paulo, Abril Cultural: 269-273.

Albaladejo, T. (1986), Teoría de los mundos posibiles y macroestructura narrativa. Alicante, Universidade de Alicante.

Albaladejo, T. (1992), Semántica de la narración: la ficción realista. Madrid, Taurus.

Albérès, R. M. (1972), Métamorphoses du roman. Paris, Albin Michel.

Almeida, J. F. (1997), Bíblia Sagrada. Rio de Janeiro, Fecomex (Ed. Revisada e corrigida).

Alves, C. C. (2010) "Vestígios do trágico em Mário de Carvalho”. Navegaçôes 3. 1: 53-58.

Anacleto, M. T. (1996), “(Sub)versions du "cliché” romanesque au XVII siècle: le "roman bourgeois" de Furetière”, Confluências 14: 97-109.

Angelini, P. R. K. (2011) "Recensão de Carvalho, M. A arte de morrer longe. Lisboa, Caminho, 2010. 128p.”. Navegaçōes 4. 1: 131-133.

Arnaut, A. P. (2001), "Donas e donzelas n'a Demanda do Santo Graal”, Santa Barbara Portuguese Studies. Califórnia, n. 5: 29-71. 
Aristófanes (21989), A Paz. Tradução de Silva. M. F. Coimbra, Instituto Nacional de Investigação Científica.

Aristófanes (2006), As Aves. Tradução de Silva, M. F. Lisboa, Edições 70.

Aristóteles (1986), Poética. Tradução de E. Sousa. Lisboa, Fundação Gulbenkian.

Arnaut, A. P. (2002), Post-Modernismo no romance português contemporâneo. Fios de Ariadnemáscaras de Proteu. Coimbra, Almedina.

Assis, A. K. T. (2008), Arquimedes, o centro de gravidade e a lei da alavanca. Montreal, Apeiron Montral.

Auerbach, E (1976), Mimesis (A representação da realidade na literatura ocidental). São Paulo, Perspetiva [1 $1^{\text {a }}$ ed., 1946].

Aurélio, Marco (1971), Pensamentos. Versão de João Maia. Lisboa, Editorial Verbo.

Bakhtine, M. (1970), La Poétique de Dostoievsky. Paris, Éd. du Seuil.

Bakhtine, M. (1981), Dialogic imagination: four essays. Austin, University of Texas Press.

Bakthine, M. (1981), Problemas da poética de Dostoievski. Trad. port. Paulo Bezerra. Rio de Janeiro, Ed. Forense-Universitária.

Benjamin, W. (1985), "Sobre o conceito de História. Tradução de Sérgio Paulo Rouanet”. In: Obras escolhidas. Magia e técnica, arte e política. São Paulo, Editora Brasiliense: 222-232.

Bessière, J. (2010), Le roman contemporain ou la problemacité du monde. Paris, PUF.

Beye, C. R. (1964), "Homeric battle narrative and catalogues", Harvard Studies in Classical Philology 68: 345-373.

Bergson, H. (2001), O riso: ensaio sobre a significação da comicidade. Trad. port. Ivone C. Benedetti. São Paulo, Martins Fontes.

Bhabha, H. K. (1998), O local da cultura. Belo Horizonte, Editora UFMG.

Bianchet, S. B. (2004), Petrônio. Satyricon. Edição bilíngüe. Belo Horizonte, Crisálida.

Bougnoux, D. (1991), "Le principe d'identification”. In Personnage et Histoire Littéraire. Toulouse, Presses Universitaires du Mirail: 187-195.

Brandão, J. L. (2001), A poética do Hipocentauro: Literatura, sociedade e discurso ficcional em Luciano de Samósata. Belo Horizonte, Ed. UFMG.

Brasete, M. F. (2003), “A crítica às mulheres no fr. 7 de Semónides de Amorgos”. In: Mora, C. M. (ed.), Sátira, Paródia e Caricatura: da Antiguidade aos nossos dias. Aveiro, Universidade de Aveiro: 39-56.

Brauner, E. F. (2009), “" Era bom que trocássemos umas ideias sobre o assunto”: ironia de um narrador e discussão do romance", Revista Electrónica de critica e teoria de literaturas. Dossiê: o romance português e o mundo contemporâneo 5. 2. Porto Alegre: 1-9.

Buescu, H. (1995), A Lua, a Literatura e o Mundo. Lisboa, Cosmos. 
Buescu, M. L. C. (1979), Aspectos da herança clássica na cultura portuguesa. Lisboa, Instituto de Cultura Portuguesa.

Camôes, L. (1979), Os Lusíadas. Prefácio de Hernâni Cidade. São Paulo, Abril Cultural.

Carcopino, J. (1993), La vida cotidiana en Roma en el apogeo del imperio, trad. esp. Madrid, Ediciones Temas de Hoy.

Cardoso Bernardes, J. A. (1988), O Bucolismo Português. A égloga do Renascimento e do maneirismo. Coimbra, Livraria Almedina.

Carvalho, M., (2003), "Mário de Carvalho: crónica do aturdimento". JL - Jornal de Letras, Artes e Ideias 864, 12/11: 12.

Ceia, C. (2007), A Construção do romance (Ensaios de literatura comparada no campo dos estudos anglo-portugueses). Coimbra, Almedina.

Chevalier, J., Gheerbrant, A. (1994), Dicionário dos Símbolos, trad. port., Lisboa, Editorial Teorema.

Colaço, J. (1995), “Mário de Carvalho”, Biblos. Enciclopédia verbo, I, s.u.

Compagnon, A. (2001), O demônio da teoria: Literatura e senso comum. Belo Horizonte, Editora UFMG.

Constâncio, N. (2007), Ruinas e incertezas em "Um Deus passeando pela brisa da tarde”, de Mário de Carvalho. Lisboa, Edições Colibri.

Costa, L. S. (1995), “Era Bom que Trocássemos Umas Ideias Sobre O Assunto, de Mário de Carvalho. A Arquitectura, A Violência”. In: Público/Leituras, 11 de Novembro:10.

Cotrim, J. P. (1996), Entrevista a Mário de Carvalho: "Alguma coisa me perturba”. Ler/Livros e Leitores 34: 45.

Cotrim, J.P. (1996), "Mário de Carvalho. O Mistério da Literatura”, entrevista ao autor. LER 34, Primavera.

Cristóbal, V. (1992), "Búsqueda de campo, hastío de ciudad. Pasión antigua y contemporánea”. In: Guzmán, A. et alii (ed.), Aspectos modernos de la Antigüedad y su aprovechamiento didáctico. Madrid, Ediciones Clásicas: 131-143.

Davison, M. (1976), "The thematic use of ekphrasis in the ancient novel”, in Erotica antiqua. Acta of the International Conference on the Ancient Novel. Bangor, ICAN: 32-33.

Devereux, G. (1975), Dreams in Greek tragedy. Oxford, Basil Blackwell.

Dijksterhuis, E. J. (1987), Archimedes. Translated by C. Dikshoorn. Princeton University Press.

Diogo, A. A. L. (1997), "Exórdio". In: Biblos- Enciclopédia Verbo das Literaturas de Lingua Portuguesa. Lisboa, São Paulo, Verbo.

D’Onofrio, S. (1978), Poema e Narrativa: estruturas. São Paulo, Duas Cidades. 
Duncan, T.S. (1935), “The deus ex machina in Greek Tragedy”. Philological Quarterly 14: $126-141$.

Dunn, F. M. (1985), Euripidian Endings: a Study of the Choral Exit, the Action, the Concluding Prophecy and the Deus ex Machina. Yale University: 111-167.

Eco, U. (1979), Leitura do Texto Literário. Lector in Fabula. Trad. Mário Brito. Lisboa, Presença.

Entrevista com Mário de Carvalho http://www.homemmag.pt/pt/index.php/arte-e-literatura/arquivo-arte-literatura/87-luisa-costa-gomes-entrevista-mario-de-carvalho

Ernout, A. ( $\left.{ }^{11} 1993\right)$, Pétrone. Le Satyricon. Paris, Les Belles Lettres.

Ernout A, Meillet, A. ( $\left.{ }^{4} 1967\right)$, Dictionnaire etymologique de la langue latine: histoire des mots. Paris, Librairie C. Klincksieck.

Errandonea, I. (1954), Diccionario del mundo clásico. Barcelona, Editorial Labor.

Eschilo ( $\left.{ }^{4} 2000\right)$ I sette contro Tebe. Con testo a fronte. Introd. Umberto Albini. Trad. Ezio Savino. Milano, Garzanti Editore.

Feijóo, B. (1998), Um Não Sei Quê. Lisboa, Vega [1746].

Ferreira, C. (2003), “Mário de Carvalho. A arte de bem iludir o leitor”. In: Rodapé: 45-51.

Ferreira, P. S. (1999), “A paródia e as suas implicações didácticas”. In: Torrão, J. M. N. (ed.), III Colóquio Clássico - Actas. Aveiro, Universidade de Aveiro: 113-137.

Ferreira, P. S. (2000), Os elementos paródicos no Satyricon de Petrónio e o seu significado. Lisboa, Colibri.

Ferreira, P. S. (2003), “Paródia ou paródias?”. In: Mora, C. M. (ed.), Sátira, Paródia e caricatura: da Antiguidade aos nossos dias. Aveiro, Universidade de Aveiro: 279-300.

Fialho, M. C. (1992), Luz e trevas no teatro de Sófocles. Coimbra, Instituto Nacional de Investigação Científica.

Figueiredo, M. N. (2006), "Com humana crueldade se tece um conto. A propósito de Homenagem ao Papagaio Verde”. In: Santos, G. (ed.) Jorge de Sena: Ressonâncias e Cinqüenta Poemas. Rio de Janeiro, 7Letras.

Fowler, D. P. ((1991), "Narrate and describe: the problem of ecphrasis", Journal of Rhetorical Studies 81: 25-35.

Frow, J. (1986), “Spectacle Binding: On Character”. Poetics Today 7. 2: 227-250.

Gaffiot, F. (1934), Dictionnarie Illustré Latin-Français. Paris, Librairie Hachette.

Garrett, A. (1973), Viagens na minha Terra. Rio de Janeiro, Editora Três.

Genette, G. (1972), Figures III. Paris, Ed. du Seuil.

Gennete, G. (1997), L'Cuvre de l'Art. La Relation Esthétique, II. Paris, Ed. du Seuil.

Genette, G. (2004), Métalepse. Paris, Ed. du Seuil.

Gomes da Torre, M. (1992), “Acerca da tradução da metáfora”. Linguas e Literaturas 9: 209-226. 
Grimal, P. (s/d), Dicionário de Mitologia Grega e Romana. Lisboa.

Guillén, J. (1977), Vrbs Roma - vida e costumbres de los romanos, vol. I: La vida privada. Salamanca, Ediciones Sígueme.

Guthrie, W. K. C. (1976), Les Sophistes. Paris, Payot.

Halliwell, S. (1968), Aristotle's Poetics. Chicago and London.

Hamon, P. (1976), “O que é a descrição?”. In: Seixo, M. A. (ed.), Categorias da narrativa. Lisboa, Arcádia: 61-83.

Hardwick, L. (2003), Reception Studies. Greece and Rome. New Surveys in the Classics. Oxford, Oxford University Press. [recensão do livro por Martin M. Winkler, in Bryan Mawr Classical Review 2004].

Heródoto. (2002), Histórias. Livro I. Tradução de Ferreira, J. R., Silva, M. F. Lisboa, Ediçóes 70. Heródoto (1997), Histórias. Livro III. Tradução de Silva, M. F., Abranches, C. Lisboa, Ediçóes 70. Heródoto (2000), Abranches, C., Histórias. Livro IV. Tradução de Silva, M. F., Abranches, Lisboa, Edições 70.

Homero (2003), Odisseia. Tradução de Frederico Lourenço. Lisboa, Livros Cotovia.

Homero (2005), Ilíada. Tradução de Frederico Lourenço. Lisboa, Livros Cotovia.

Hoorn, J. F., and Konijn, E. A. (2003), "Perceiving and experiencing fictional characters: An integrative account”. Japanese Psychological Research 45. 4: 250-268.

Horácio (1975), Arte Poética. Tradução de R. M. R. Fernandes. Lisboa, Clássica Editora.

Hutcheon, L. (1977), “Modes et formes du narcisisme littéraire”. Poétique 29: 90-106.

Hutcheon, L. (1984), Narcissistic Narrative. The Metafictional Paradox. New York and London, Methuen.

Hutcheon, L. (1985), A Theory of Parody. The Teachings of Twentieth Century Art Forms. New York \& London, Methuen; (1989), Uma teoria da paródia, trad. port. Lisboa, Ediçóes 70.

Hutcheon, L. (1988), A poetics of Postmodernism. History, Theory, Fiction. New York/London, Routledge; (1991), Poética do Pós-Modernismo. Trad. Ricardo Cruz. Rio de Janeiro, Imago.

Hutcheon, L. (2000), Teoria e Política da Ironia. Trad. port. Julio Jeha. Belo Horizonte, Editora UFMG.

Immerwahr, H. R. (1966), Form and thought in Herodotus. University of North Carolina.

Izaac, H. J. ( ${ }^{3} 1969$, 1973), Martial. Épigrammes, I-II. Paris, Les Belles Lettres.

Jauss, H. R. (1986), Experiencia y Hermeneutica Literaria. Ensayos en el campo de la experiencia estétca. Madrid, Taurus, [1977].

Jenny, L. (1979), "A estratégia da forma”, Poétique. Revista de teoria e análise literárias. Trad. port. Clara C. Rocha. Coimbra, Almedina: 5- 49. 
Jerome, K. J. , “Three men on the Brummel'. In: http://www.gutenberg.org/catalog/world/ readfilefk_files $=2061881$

Jourdan, P. (1996), "Paul Valéry chasseur de perroquets", Confluências 14: 51-59.

Júdice, N. (1997), Viagem por um século de Literatura Portuguesa. Lisboa, Relógio d'Água.

Julien, Y. (1998), Aule-Gelle. Les nuits attiques, IV. Paris, Les Belles Lettres.

Jurado, F. G. (1999), "Apuntes para una historia prohibida de la literatura latina en el siglo XX: La voz de los lectores no académicos”. In: Morán, M. C. A.; Iglesias Montiel, R. M. (eds.), Contemporaneidad de los clásicos en el umbral deI tercer milenio. Actas deI Congreso Internacional Contemporaneidad de los clásicos: La tradición greco-latina ante el siglo XXI. La Habana, Universidad de Murcia: 77-85.

Kerferd, G. B. (2003), O movimento sofista. Trad. port. Margarida Oliva. São Paulo, Ediçôes Loyola.

Kirk, D. M. (1960), The digression, its use in prose fiction from the Greek romance through the eighteenth century. Stanford University.

Kristeva, J. (1974ª), Introdução à semanálise. São Paulo, Perspectiva.

Kuester, M. (1992), Framing Truths - Parodic Structures in Contemporary English-Canadian Historical Novels. Toronto/London, Toronto University Press.

Lausberg, H. (1963), Elementos de retórica literária. Trad. port. Raul M. Rosado Fernandes, Lisboa, Gulbenkian.

Leão, D. F. (1996), “Trimalquião: a humanitas de um novo-rico”. Humanitas 48: 161-182.

Leão, D. F. (1997), “Trimalquião à luz dos Caracteres de Teofrasto”. Humanitas 49: 147-167.

Leão, D. F. (1998), As Ironias da Fortuna. Sátira e Moralidade no Satyricon de Petrónio. Lisboa, Colibri.

Leão, D. F. (2004), “Zoilo e Trimalquião, duas variaçôes sobre o tema do novo-rico”. Humanitas 56: 191-208.

Leão, D. F. (2004a), “O Satyricon de Petrónio e a crise dos paradigmas tradicionais”. In: Nascimento, A. (ed.), Antiguidade Clássica: Que fazer com este património?. Lisboa, Centro de Estudos Clássicos: 233-242.

Leão, D. F. (2005), Petrónio. Satyricon. Lisboa, Cotovia.

Lepaludier, L (2002), Métatextualité et métafiction. Théorie et analyses, Presses Universitaires de Rennes, CRILA.

Levi, P. (1988), É isto um homem? Rio de Janeiro, Rocco.

Lévy, E. (1983), "Le théâtre et le rêve: le rêve dans le théâtre d'Eschyle", in Zehnacker, H. (ed.), Théatre et spectacles dans l'Antiquité. Actes du Colloque de Strasbourg. Leiden: 141-168.

Lopes, S. R. (2003), Literatura, Defesa do atrito. Lisboa, Copiart. 
Lourenço, E. ('1982), "Da literatura como interpretação de Portugal”. In O Labirinto da Saudade (Psicanálise Mitica do Destino Português). Lisboa, D. Quixote: 85-126.

Lourenço, F. (2003), Homero. Odisseia. Lisboa, Cotovia.

Luciano (1996), Uma história verídica. Tradução de C. Magueijo. Lisboa, Editorial Inquérito Limitada.

Lukács, G. (1989), Théorie du roman. Paris, Flammarion [1916].

"Na Lusitânia com Mário de Carvalho (História, paródia e ironia em Quatrocentos mil sestércios e Um deus passeando pela brisa da tarde)". In Veredas 5 (2002) 211-224.

Macedo, A. G. (2008), Narrando o pós-moderno: reescritas, revisôes, adaptaçôes. Braga Universidade do Minho.

Machado, J. P. (1995), Dicionário etimológico da Língua Portuguesa. Lisboa, Livros Horizonte.

Malina D. (2002), Breaking the frame: metalepsis and the construction of the subject. Columbus, Ohio State UP.

Margolin, U. (2005), “Character”. In: Herman, D., Jahn M., Ryan, M.-L. (eds.), Routledge Enciclopedia of Narrative Theory. London/New York, Routledge: 54-57.

Marinho, M. F. (1996), "O sentido da história em Mário de Carvalho", Revista da Faculdade de Letras. Linguas e Literaturas: 257-267.

Marinho, M. F. (2010), "À la recheche de l'identité perdue. Essai sur la crise d'identité dans le roman portugais contemporain”. In: Besse, M. G. \& Ralle, M. (eds.), Les Grands Récits: Miroirs Brisés? Paris, Índigo:186-198.

Martin, F. (1987), Les mots latins. Paris, Hachette.

Martins, J. C. O. (2011), "Mário de Carvalho e a reflexão metaficcional sobre o futuro do romance”. Diacrítica. Dossiê Literatura e Religiāo 25/3: 23-44.

Martins, J. C. O. (2011), “Pensar Portugal - ironia, paródia e desencanto: Mário de Cavalho e o retrato melancólico de um país". In: Carvalho da Silva, J. A., Martins, J. C. O., Gonçalves, M. (eds.), Pensar a Literatura no Séc. XXI. Braga, Univ. Católica Portuguesa: 463-478.

Martins, J. C. O. (s.d.), "La barbarie de l'ignorance dans la culture postmoderne et la fiction de Mário de Carvalho". In: De l'Extrême: pratiques du contemporain dans les mondes ibériques et ibéro-américains, Paris, CRIMIC [em publicação].

Martins, M. F. (1983), Sombras e transparências da literature. Lisboa, INCM.

Martins, Maria João (2003), "Mário de Carvalho: crónica de um aturdimento" [entrevista], JL - Jornal de Letras, Artes e Ideias, no 864, 12 novembro, p. 12.

Mead, G. (1990), “The Representation of Fictional Character”. Style 24. 3: 440.

Medeiros, W. (1997), "Do desencanto à alegria: o Satyricon de Petrónio e o Satyricon de Fellini”. Humanitas 49: 169-175. 
Melanda, P. C. O. (2001), Pela mão de Clio. A reescrita da História em Mário de Carvalho. Aveiro. 38. Dissertação de Mestrado em Estudos Portugueses, apresentada à Universidade de Aveiro. Exemplar em CDRom.

Melero Bellido, A. (2001), "La utopia cómica o los límites de la democracia”, Cuadernos de Literatura Griega y Latina 3: 7-25.

Melero Bellido, A. (2004), "La lengua de la utopia". In: López Eire, A., Guerrera, A. R. (Eds.). Registros Lingüísticos en las lenguas clásicas. Salamanca, Ediciones Universidad Salamanca: 149-172.

Mendes, A. M. G. (1999), "Cultura clássica em Um Deus Passeando pela brisa da tarde de Mário de Carvalho”, III Colóquio Clássico - Actas, Aveiro: 347-363.

Mendes, A. M. G. (2005), “Trimalquião, os coronéis e a piscina: retrato impiedoso de um país em crise”. Ágora. Estudos Clássicos em Debate. Aveiro 7: 129-150.

Mendes, J. P. (1997), Construção e Arte das Bucólicas de Virgílio. Coimbra, Almedina.

Mendonça, F. (1997), “A Paixão do Conde Fróis”. Colóquio/Letras 99. Setembro-Outubro.

Mexia, P. (2005), “O Manuel Germano”. Diário de Notícias. Artes, 17 de Junho: http:// dn.sapo.pt/2005/06/17/artes/o_manuel_germano.html

Moisés, M. ('1973), A criação literária: introdução à Problemática da Literatura. São Paulo, Melhoramentos.

Mora, C. M. (2003), “A outra resposta de Tirésias”. In: Mora, C. M. (ed.), Sátira, Paródia e caricatura: da Antiguidade aos nossos dias. Aveiro, Universidade de Aveiro: 7-13.

Morais e Silva, A. (1953), Grande Dicionário da Lingua Portuguesa. Lisboa, Confluência.

Mourão, J. A. (1998), "Posfácio”, a Feijóo, Benito - Um Não Sei Quê. Lisboa, Vega.

Nickel, R. (1999), “Lucian's True Story: impressions of a fancy voyage”, Euphrosyne 27: 249-257.

Niederauer, S. (2008), "Era bom que trocássemos umas ideias sobre o assunto ou $\mathrm{O}$ simulacro da narrativa na pós-modernidade”. Letras de Hoje 43. 4: 83-88.

Oliveira, B. S. (1997), Eurípides. Hipólito. Brasília, Editora UNB.

Onelley, G. B. (2004), “A resistência da nau: cidade na luta pelo poder”. Calíope 12: 33-42.

Otte, G. (1996), "Rememoração e citação em Walter Benjamin". Revista de Estudos de Literatura 4. Belo Horizonte, Centro de Estudos Literários (CEL), Faculdade de Letras da UFMG: 211-223.

Pereira, E. (2003), "Viagens na minha terra: ciladas da representação". Revista do Centro de Estudos Portugueses 23 n. 32: 61-68.

Pereira, S. M. (2008), “Poética dos sonhos e das visōes em estado de vigília - I”, Humanitas 60: 11-28.

Pereira, S. M. (2009), "Poética dos sonhos e das visōes em estado de vigília - II”, Humanitas 61: 5-18.

Perelman, C. O. (1993), O Império Retórico: Retórica e Argumentação. Tradução de Fernando Trindade e Rui Alexandre Grácio. Porto, Ediçóes Asa. 
Perrin-Naffakh. A.-M. (1996), "Le langage cliché: aveu d'usure ou pouvoir d'écho". Confluências 14: 7-14.

Perrone-Moisés, L. (1979), “A intertextualidade crítica”. Poétique. Revista de teoria e análise literárias. Trad. port. Clara C. Rocha. Coimbra, Almedina: 209-230.

Pimentel, C. S. (2001), "O latim nas literaturas portuguesa e francesa: instrumentos, métodos e agentes de ensino”, Ágora, Estudos Clássicos em Debate 3: 183-185.

Piwnik, M.-H. (1998), "Mário de Carvalho: crónica de um desfecho anunciado", Veredas 1, Porto: 317-325.

Piwnik, M.-H. (2004), “De Sienkiewicz a Mário de Carvalho: Duas construções da História”. In: Literatura e História. Actas do Colóquio Internacional, Porto, vol. II: 139-144.

Platão ( $\left.{ }^{12} 2010\right)$, República. Trad. Maria Helena da Rocha Pereira. Lisboa, Fundação Calouste Gulbenkian.

Préchac, F. (1987), Sénèque. Lettres a Lucilius, II. Paris, Les Belles Lettres.

Queirós, E. de (s./d.), Os Maias. Lisboa, Livros do Brasil.

Queirós, E. de (2000), O Crime do Padre Amaro. Ed. crítica de Carlos Reis e M. Rosário Cunha. Lisboa, IN-CM.

Rabaté, E. (1996), "Henri Michaux et le cliché: résistance et fascination”. Confluências 14: 61-75.

Raimond, M. (1989), Le Roman. Paris, Armand Colin.

Reis, C. (1996), "Mário de Carvalho. Incitação ao romance”. Jornal de Letras 28 Agosto: 22-23.

Reis, C. (1997), "Fábula”. In: Biblos-Enciclopédia Verbo das Literaturas de Lingua Portuguesa. Lisboa, São Paulo, Verbo: 462-463.

Reis, C. (2005), História crítica da literatura portuguesa, vol. IX (Do neorrealismo ao postmodernismo). Lisboa, Verbo: 287-318.

Reis, C., Macário Lopes, A. C. (72007), Dicionário de narratologia. Coimbra, Almedina.

Ricoeur, P. (1983), Temps et Récit. T.I. Paris, Ed. du Seuil.

Rio Torto, G. M. (1996), "Linguagem e clichê", Confluências 14: 159-175.

Robilliard, M.-A. (2002), Água em pena de pato de Mário de Carvalho. Um teatro do desencanto. Trad. port. Manuel Ruas. Lisboa, Editorial Caminho.

Rocha Pereira, M. H. (1955), Concepçōes Helénicas de felicidade no além: de Homero a Platão. Coimbra, Maranus.

Rocha Pereira, M. H. (1980), Poesia Grega Arcaica. Coimbra, Instituto de Estudos Clássicos.

Rocha Pereira, M. H. (1984), Estudos de História da Cultura Clássica, vol. II (Cultura Romana). Lisboa, Fundação Calouste Gulbenkian.

Rocha Pereira, M. H. ('1994), Romana - Antologia da Cultura Latina. Coimbra, Universidade de Coimbra. 
Rocha Pereira, M. H. ( $\left.{ }^{10} 2006\right)$, História da Cultura Clássica, I (Cultura Grega). Lisboa, Fundação Calouste Gulbenkian.

Rodrigues, L. G. (2005), “A Radioestesia”. In http://rprecision.logspot.com/2005/06/radiestesia.html Rose, M. A. (1979), Parody and meta-fiction. London, Croom Helm.

Sant'Anna, A. R. ('1985), Parodia, paráfrase \& cia. São Paulo, Ática.

Santos, R. B. (2009), Aspectos da Herança Clássica em Mário de Carvalho. Belo Horizonte, Faculdade de Letras da UFMG, 2009. [versão policopiada].

Saramago, J. (1989), História do Cerco de Lisboa. Lisboa, Caminho.

Saramago, J. (1990), "História e Ficção”. Jornal de Letras, Artes e Ideias, 6 de Março.

Schaeffer, J. M. (1992), L'art de l'àge moderne. L'esthétique et la philosophie de l'art du XVIIIème siècle à nos jours. Paris, Gallimard.

Schmidt, W. (1963), Der Deus Ex Machina bei Euripides. Tübingen University.

Schwartz, J. (1981), Murilo Rubião: A poética do Uroboro. São Paulo, Editora Ática.

Scodel, R. (1999), Credible impossibilities. Conventions and strategies of verisimilitude in Homer and Greek tragedy. University of Michigan Press.

Sedlmayer, S., "Sinais de fogo, aviso de incêndio: ideias estéticas, históricas e literárias em Jorge de Sena e Walter Benjamin”. In: Revista Literatrua e Autoritarismo. Dossiê Walter Benjamin e a Literatura brasileira. Santa Maria, Universidade Federal de Santa Maria/ RS. Disponível em http://w3.ufsm.br/grpesqla/revista/dossie05/art_02.php

Seel, M. (1992), "Le langage de l'art est muet". In: Bouchindhomme, Ch., Rochlitz, R. (eds.), L'art Sans Compas. Redéfinitions de l'Esthétique. Paris, Éd. du Cerf.

Segurado e Campos, J. A. (1991), Cartas a Lucílio, Lisboa, Fundação Calouste Gulbenkian.

Seixo, M. A. (1995), "Mário de Carvalho. Romance, Humanismo e BD”, JL - Jornal de Letras, Artes e Ideias, 12. 4: 24-25.

Sena, J. http://www.letras.ufrj.br/lerjorgedesena/port/antologia/ficcao-e-teatro/texto.php?id=319

Sequeira, M. G. R. (1996), Aproximação a uma Leitura do Risivel em A Paixão do Conde de Fróis. Tese de Mestrado apresentada à Faculdade de Letras da Universidade do Porto (dact.).

Settis, S. (2006), El futuro de lo 'clásico'. Traducción de Andrés Soria Olmedo. Madrid, Abada Editores.

Silva, M. F. (1987), Critica do teatro na comédia antiga. Coimbra, INIC.

Silva, M. F. (2005), Ensaios sobre Euripides. Lisboa, Cotovia.

Silva, M. F. (2007), "A porta na comédia de Aristófanes: uma entrada para a utopia”. In: Ensaios sobre Aristófanes. Lisboa, Cotovia: 257-274. 
Silva, M. F. (2008), "Mensagens, cartas e livros no teatro grego antigo", in Matos, M. C. (ed.), Helénicos. Estudos em homenagem do Prof. Jean-Pierre Vernant (1914-2007). Lisboa, Ediçôes Távola Redonda: 227-260.

Silva, M. F. (2009), Utopias e distopias. Coimbra, Imprensa da Universidade.

Silvestre, O. M. (1998), "Mário de Carvalho: Revolução e Contra-revolução ou um passo atrás e dois à frente”. Colóquio/Letras 147/148: 209-229.

Silvestre, O. e Diogo, A. L. (1998), "Entrevista a Mário de Carvalho", in <http://www. ciberkiosk.pt>, arquivo, $\mathrm{n}^{\circ} 1$ (15 pp.).

Simões, M. J. (2006), “Atrevidas e desbordantes: as personagens em Mário de Carvalho”. In Figuras da Fiç̧ão. Coimbra, Centro de Literatura Portuguesa: 79-92.

Spivak, G. Ch. ('2003), “Can the subaltern speak?” In: Asheroft, B., Griffith, G., Tiffin, H. (eds.), The post-colonial studies reader. New York, Routledge.

Spivak, G. Ch. (1998), "Puede hablar elsujeto subalterno?”. Orbis Tertius 3. 6: 1-44.

Sterne, L. (1860), The Works of Lawrence Sterne. London, Henry Bohn.

Thomasson, A. (2003), "Fictional Characters and Literary Practices". British Journal of Aesthetics 43. 2, April:138-157.

Todorov, T. (1999), O homem desenraizado. Trad. Christina Cabo. Rio de Janeiro, Record.

Torrão, J. M. N. (ed.) (1999), III Colóquio Clássico. Aveiro, Universidade de Aveiro.

Tosi, R. (2000), Dizionario delle sentenze latine e greche. Milano, Biblioteca Universale Rizzoli.

Trindade, L. (2004), “Os excessos de Abril”, História 65: 20-31.

Valente, A. M. (2004), Aristóteles. Poética. Lisboa, Gulbenkian.

Várzeas, M. (2001), Silêncios no teatro de Sófocles, Lisboa, Cosmos.

Villeneuve, F. (1970), Horace. Odes et Epodes, I. Paris, Les Belles Lettres.

Xavier, L. G. (2007), O discurso da ironia. Lisboa, Novo Imbondeiro.

Walton, K. (1990), Mimesis as Make-Believe: On the Foundations of the Representational Arts. Cambridge Mass., Havard University Press.

Waugh, P. (2003), Metafiction. The Theory and Practice of Self-Conscious Fiction. London \& New York, Routledge [1984].

Wesseling, E. (1991), Writing History as a Prophet. Postmodernist Innovations of the Historical Novel. Amsterdam/Philadelphia, John Benjamins.

Wolff, F. (2004), “Quem é bárbaro?”. In: Novaes, A. (ed.), Civilização e Bárbarie. São Paulo, Companhia das Letras: 19-43.

Woods, J. (1974), The Logic of Fiction. Paris, Mouton; (2010), A Mecânica da fiç̧âo. Lisboa: Quetzal. Zagajewski, A. (2003), En la belleza ajena, trad. esp. A. E. Diaz-Pintado Hilario, Valencia, Pre-Textos. 